\title{
Influence of postoperative sagittal balance and spinopelvic parameters on the outcome of patients surgically treated for degenerative lumbar spondylolisthesis
}

\author{
Ingrid Radovanovic, MD, ${ }^{1,3}$ Jennifer C. Urquhart, PhD, 2,3 Venkat Ganapathy, MD,,3 \\ Fawaz Siddiqi, MD, ${ }^{1-3}$ Kevin R. Gurr, MD, ${ }^{1-3}$ Stewart I. Bailey, MD, ${ }^{1-3}$ and \\ Christopher S. Bailey, MD1-3
} 1Division of Orthopaedics, Department of Surgery, Schulich School of Medicine and Dentistry, Western University; ' 2 awson
Health Research Institute; and ${ }^{3}$ London Health Science Centre, London, Ontario, Canada

\begin{abstract}
OBJECTIVE The object of this study was to determine the association between postoperative sagittal spinopelvic alignment and patient-rated outcome measures following decompression and fusion for lumbar degenerative spondylolisthesis.

METHODS The authors identified a consecutive series of patients who had undergone surgery for lumbar degenerative spondylolisthesis between 2008 and 2012, with an average follow-up of 3 years (range 1-6 years). Surgery was performed to address the clinical symptoms of spinal stenosis, not global sagittal alignment. Sagittal alignment was only assessed postoperatively. Patients were divided into 2 groups based on a postoperative sagittal vertical axis $(\mathrm{SVA})<50$ $\mathrm{mm}$ (well aligned) or $\geq 50 \mathrm{~mm}$ (poorly aligned). Baseline demographic, procedure, and outcome measures were compared between the groups. Postoperative outcome measures and postoperative spinopelvic parameters were compared between groups using analysis of covariance.

RESULTS Of the 84 patients included in this study, $46.4 \%$ had an SVA $<50 \mathrm{~mm}$. Multiple levels of spondylolisthesis ( $p$ $=0.044)$, spondylolisthesis at the L3-4 level $(p=0.046)$, and multiple levels treated with fusion $(p=0.028)$ were more common among patients in the group with an SVA $\geq 50 \mathrm{~mm}$. Patients with an SVA $\geq 50 \mathrm{~mm}$ had a worse SF-36 physical component summary (PCS) score $(p=0.018)$, a worse Oswestry Disability Index (ODI; $p=0.043)$, and more back pain $(p=0.039)$ than those with an SVA $<50 \mathrm{~mm}$ after controlling for multiple levels of spondylolisthesis and multilevel fusion. The spinopelvic parameters differing between the $<50-\mathrm{mm}$ and $\geq 50-\mathrm{mm}$ groups included lumbar lordosis (LL; $56.4^{\circ} \pm$ $4.7^{\circ}$ vs $49.8^{\circ} \pm 4.3^{\circ}$, respectively, $\left.p=0.040\right)$ and $L L<$ pelvic incidence $\pm 9^{\circ}(51 \%$ vs $23.1 \%$, respectively, $p=0.013)$ after controlling for type of surgical procedure.
\end{abstract}

CONCLUSIONS Data in this study revealed that patient-rated outcome is influenced by the overall postoperative sagittal balance as defined by the SVA.

https://thejns.org/doi/abs/10.3171/2016.9.SPINE1680

KEY WORDS vertical sagittal balance; degenerative lumbar spondylolisthesis; spinopelvic parameter; health-related quality of life; radiographic parameters

$\mathrm{S}$ AGITTAL balance and pelvic parameters are well recognized as important for the preoperative planning and surgical outcome of adult spinal deformity and isthmic spondylolisthesis. ${ }^{1,711,18,19}$ A positive sagittal vertical axis (SVA) following the correction of adult spinal de- formity is correlated with suboptimal functional outcome and quality of life. ${ }^{5,711,15,18,19}$ Pelvic position plays a critical role in maintaining sagittal posture and alignment. Failure to account for spinopelvic alignment when treating spinal deformity increases the risk for spinal misalignment, de-

ABBREVIATIONS HRQOL = health-related quality of life; ICC = intraclass correlation coefficient; LL = lumbar lordosis; $M C S=$ mental component summary; NRS = numeric rating scale; $\mathrm{ODI}=$ Oswestry Disability Index; $\mathrm{PCS}=$ physical component summary; $\mathrm{PI}=$ pelvic incidence; $\mathrm{PT}=$ pelvic tilt; $\mathrm{SS}=$ sacral slope; $\mathrm{SVA}=$ sagittal vertical axis; TK = thoracic kyphosis; ZCQ = Zurich Claudication Questionnaire.

SUBMITTED January 14, 2016. ACCEPTED September 13, 2016.

INCLUDE WHEN CITING Published online January 20, 2017; DOI: 10.3171/2016.9.SPINE1680. 
compensation, and treatment failure. ${ }^{1}$ Achieving an SVA that is $<50 \mathrm{~mm}$ in the adult scoliosis population has been recommended for optimal postoperative health-related quality of life (HRQOL).,16,20

Degenerative spondylolisthesis with associated spinal stenosis remains a very common indication for spinal surgery, which has been shown to be superior in outcome compared to nonoperative treatment. ${ }^{24}$ Several studies have investigated the relationship between pelvic parameters and the development of degenerative spondylolisthesis. ${ }^{2,12,19}$ To our knowledge, however, few studies have attempted to demonstrate an association between sagittal balance and postoperative outcome specific to the degenerative lumbar spondylolisthesis patient cohort. ${ }^{10,13}$ Specifically, the importance of establishing an SVA $<50 \mathrm{~mm}$ in the degenerative lumbar spondylolisthesis population, as it is in the deformity cohort, remains unknown.

The objective of the current investigation was to determine whether postoperative sagittal balance and spinopelvic alignment affects patient-rated outcome measures after surgical treatment of spinal stenosis in patients with lumbar degenerative spondylolisthesis.

\section{Methods \\ Patients}

We hypothesized that patients with an SVA $\geq 50 \mathrm{~mm}$ would have a worse functional outcome and HRQOL than those with an SVA $<50 \mathrm{~mm}$. The $50-\mathrm{mm}$ discriminator is based on published findings within the spinal deformity population. ${ }^{20}$ After obtaining approval from our institutional research ethics board, we performed a retrospective review of a consecutive series of patients identified from a prospectively maintained surgical database. Patients included for analysis were those who had undergone fusion and decompression for lumbar degenerative spondylolisthesis at our institution between 2008 and 2012 to treat underlying neurogenic claudication or radiculopathy from symptomatic spinal stenosis after the failure of nonsurgical management. The primary indication for surgery was an associated severe central spinal stenosis documented on MRI. Surgery was performed via an open posterior approach and included a partial laminectomy (surgical details are listed in Table 1). Surgery was isolated to the level of spondylolisthesis, and no attempt was made to rebalance or address potential hypolordosis adjacent to the level(s) of spondylolisthesis. Three fellowship-trained spine surgeons performed all surgeries. Patients eligible for study inclusion had to have a minimum clinical and radiographic follow-up of 12 months. The postoperative radiographic and outcome measures reported were those collected on the most recent postoperative visit. Patients were excluded if they did not have degenerative spondylolisthesis (that is, isthmic spondylolisthesis), had inflammatory spine disease such as rheumatoid arthritis, progressive neurological deficit requiring urgent surgery, malignancy at the time of enrollment, previous surgery at the involved spinal level, previous lumbar fusion, or an inability to complete the questionnaires or provide follow-up (for example, lack of permanent address, substance abuse, interfering psychiatric illness).
TABLE 1. Summary of preoperative characteristics in 84 study patients

\begin{tabular}{|c|c|c|c|c|}
\hline Parameter & $\begin{array}{l}\text { Overall } \\
\text { Cohort }\end{array}$ & $\begin{array}{c}\text { SVA }<50 \\
\mathrm{~mm}\end{array}$ & $\begin{array}{c}\text { SVA } \geq 50 \\
m m\end{array}$ & $\begin{array}{c}p \\
\text { Value }\end{array}$ \\
\hline No. of patients & 84 & 39 & 45 & \\
\hline $\begin{array}{l}\text { Mean age } \pm S D \\
\text { in yrs }\end{array}$ & $71.1 \pm 9.2$ & $68.8 \pm 10.0$ & $72.3 \pm 8.3$ & 0.088 \\
\hline No. of women (\%) & $48(57.1)$ & $25(64.1)$ & $23(51.1)$ & 0.230 \\
\hline $\begin{array}{l}\text { Mean BMI } \pm \text { SD in } \\
\mathrm{kg} / \mathrm{m}^{2}\end{array}$ & $28.9 \pm 5.2$ & $28.5 \pm 5.4$ & $29.3 \pm 5.1$ & 0.505 \\
\hline $\begin{array}{l}\text { Smoking history (no. } \\
{[\%] \text { ) }}\end{array}$ & & & & 0.271 \\
\hline Yes & $4(4.8)$ & $1(2.6)$ & $3(6.7)$ & \\
\hline No & 74 (88.1) & $36(92.3)$ & $38(84.4)$ & \\
\hline Unknown & $6(7.1)$ & $2(5.1)$ & $4(8.9)$ & \\
\hline $\begin{array}{l}\text { Employment status } \\
\text { (no. [\%]) }\end{array}$ & & & & 0.518 \\
\hline Employed & $6(7.1)$ & $4(10.3)$ & $2(4.4)$ & \\
\hline Disability & $5(6.0)$ & $2(5.1)$ & $3(6.7)$ & \\
\hline Retired & $64(76.2)$ & $27(69.2)$ & 37 (82.2) & \\
\hline Homemaker & $5(6.0)$ & $3(7.7)$ & $2(4.4)$ & \\
\hline Unemployed & $2(2.4)$ & $2(5.1)$ & $0(0)$ & \\
\hline Unknown & $2(2.4)$ & $1(2.6)$ & $1(2.2)$ & \\
\hline $\begin{array}{l}\text { Spondylolisthesis } \\
\text { (no. [\%]) }\end{array}$ & & & & 0.372 \\
\hline Grade 1 & $72(85.7)$ & $32(82.1)$ & $40(88.9)$ & \\
\hline Grade 2 & $12(14.3)$ & $7(17.9)$ & $5(11.1)$ & \\
\hline Multiple levels (no. & $11(13.1)$ & $2(5.1)$ & $9(20.0)$ & $0.044^{*}$ \\
\hline
\end{tabular}

[\%])

Level of spondylolis-

thesist (no. [\%])

\begin{tabular}{lcccc} 
L3-4 & $19(22.6)$ & $5(12.8)$ & $14(31.1)$ & $0.046^{*}$ \\
L4-5 & $69(82.1)$ & $35(89.7)$ & $34(75.6)$ & 0.090 \\
L5-S1 & $4(4.8)$ & $1(2.6)$ & $3(6.7)$ & 0.378 \\
\hline - $)$ & $49.3 \pm 12.9$ & $51.2 \pm 13.0$ & $47.7 \pm 12.8$ & 0.228 \\
\hline 36 PCS & $24.7 \pm 5.7$ & $25.7 \pm 5.2$ & $23.8 \pm 5.9$ & 0.130 \\
\hline & $44.1 \pm 12.0$ & $44.2 \pm 12.0$ & $44.1 \pm 12.2$ & 0.968 \\
\hline MCS & $51.1 \pm 15.1$ & $47.8 \pm 14.5$ & $54.0 \pm 15.1$ & 0.073 \\
\hline
\end{tabular}

$\mathrm{BMI}=$ body mass index.

* $p<0.05$, SVA $<50 \mathrm{~mm}$ compared with $S V A \geq 50 \mathrm{~mm}$.

$\dagger$ A patient could have more than 1 level of spondylolisthesis.

\section{Patient-Rated Outcome Measures}

The patient-rated outcome measures used were those collected preoperatively and at the last follow-up visit, including the Oswestry Disability Index (ODI), SF-36 physical component summary (PCS) and mental component summary (MCS) scores, Zurich Claudication Questionnaire (ZCQ), and numeric rating scale (NRS) for back pain. For the SF-36 PCS and MCS, higher scores imply better functioning. ${ }^{6}$ The ODI evaluates physical disability secondary to back and/or leg pain on a scale of 0 to $100 .{ }^{13}$ The ZCQ was used to evaluate the severity of spinal stenosis symptoms. ${ }^{22}$ For the ODI and ZCQ, a higher score denotes worsening disability. The NRS for back 
pain ranges from 0 to 10 , with lower scores indicating less severe symptoms. ${ }^{8}$

\section{Radiographic Measures}

Complete radiographic evaluation, including a standing 36-inch lateral radiograph and standing lateral lumbar spine radiograph, inclusive of the femoral heads, was performed, and the data were retrospectively collected from the last follow-up visit and not collected preoperatively. Only lumbar lordosis (LL) was available for collection preoperatively. Two assessors independently measured digital images with the Centricity 2.1 computer program (GE Medical Systems) using the calibrated guide. Any difficulty assessing radiographs was resolved by further assessment from a fellowship-trained spine surgeon to reach consensus. Sagittal alignment was evaluated using standing 36-inch lateral radiographs taken from above the C-7 vertebral body to below the sacral endplate. The SVA was measured by extending a vertical plumb line from the midpoint of the C-7 vertebral body and measuring the distance between this line and the posterosuperior corner of S-1. ${ }^{1}$ Lumbar lordosis was measured using the superior endplate of L-1 and S-1. Thoracic kyphosis was measured between the superior endplate of T-4 and the inferior endplate of T-12. The instrumentation angle was measured using the superior endplate of the most cephalad vertebra in the instrumented construct and the inferior endplate of the most caudal instrumented vertebra. The pelvic parameters were measured using a standing lateral view, which included L-3 to below the femoral heads.

\section{Statistical Analysis}

Patients were divided into 2 groups based on a postoperative SVA $\geq 50 \mathrm{~mm}$ or $<50 \mathrm{~mm}$, as described previously. ${ }^{1,16,20}$ An unpaired t-test or the chi-square test was used for baseline comparison of continuous or categorical variables. The interrater variability of radiographic measurements was assessed using the intraclass correlation coefficient (ICC) based on a 2-way random-effects model utilizing absolute agreement. An analysis of covariance was conducted to compare outcome measures between patients with an SVA $<$ or $\geq 50 \mathrm{~mm}$, adjusting for baseline parameters that were significantly different in the univariate analysis. Analysis of covariance was used to compare spinopelvic parameters between groups, adjusting for type of surgical procedure. A post hoc analysis using an unpaired t-test or chi-square test was performed to compare radiographic parameters among patients with single-level spondylolisthesis and among those having multiple levels of spondylolisthesis. Pearson's correlation coefficient was used to assess the association between radiographic parameters and patient-rated outcome measures. A statistically significant difference was defined as $\mathrm{p}<0.05$.

\section{Results}

Eighty-four (60.9\%) of 138 patients satisfied all of the inclusion criteria. Of the 54 patients who were excluded, 30 patients had incomplete radiographs, 20 patients were lost to follow-up, and 4 patients declined to participate.

Preoperative demographics for the 84 patients are listed
TABLE 2. Operative treatments

\begin{tabular}{lcccc}
\hline \multicolumn{1}{c}{ Parameter } & $\begin{array}{c}\text { Overall } \\
\text { Cohort }\end{array}$ & $\begin{array}{c}\text { SVA } \\
<50 \mathrm{~mm}\end{array}$ & $\begin{array}{c}\text { SVA } \\
\geq 50 \mathrm{~mm}\end{array}$ & $\begin{array}{c}\mathrm{p} \\
\text { Value }\end{array}$ \\
\hline No. of patients & 84 & 39 & 45 & \\
\hline Type of surgery (no. [\%]) & & & & 0.732 \\
Instrumented posterolat- & $25(29.8)$ & $11(28.2)$ & $14(31.1)$ & \\
$\quad$ eral fusion & $55(65.5)$ & $27(69.2)$ & $28(62.2)$ & \\
Posterior interbody fusion & $4(4.8)$ & $1(2.6)$ & $3(6.7)$ & \\
$\quad$ Noninstrumented & & & & \\
\hline Multilevel fusion (no. [\%]) & $20(23.8)$ & $5(12.8)$ & $15(33.3)$ & $0.028^{*}$ \\
\hline Surgical level† (no. [\%]) & & & & \\
L1-2 & $1(1.2)$ & $0(0)$ & $1(2.2)$ & 0.877 \\
L2-3 & $4(4.8)$ & $1(2.6)$ & $3(6.7)$ & 0.378 \\
L3-4 & $31(36.9)$ & $8(20.5)$ & $23(51.1)$ & $0.004^{*}$ \\
L4-5 & $74(88.1)$ & $38(97.4)$ & $36(80.0)$ & $0.014^{*}$ \\
L5-S1 & $10(11.9)$ & $3(7.7)$ & $7(15.6)$ & 0.267 \\
\hline
\end{tabular}

* $p<0.05$, SVA $<50 \mathrm{~mm}$ compared with SVA $\geq 50 \mathrm{~mm}$.

$\dagger$ A patient could have more than 1 surgical level.

in Table 1. In the overall cohort the mean age at the time of assessment was $71.1 \pm 9.2$ years, and $57.1 \%$ of the patients were female. The mean follow-up was 3 years (range 1-6 years). Thirty-nine patients (46.4\%) had an SVA $<50 \mathrm{~mm}$, and $45(53.6 \%)$ had an SVA $\geq 50 \mathrm{~mm}$. The mean SVA in the $<50$-mm group was $26.0 \mathrm{~mm}$ (range -47.8 to 48.8 $\mathrm{mm}$ ) and $89.9 \mathrm{~mm}$ (range $50.3-160.5 \mathrm{~mm}$ ) in the $\geq 50-\mathrm{mm}$ group. Patients in the 2 groups were similar in age, sex, body mass index, smoking history, and employment history. Neither were baseline preoperative scores for SF-36 PCS and MCS, ODI, NRS for back pain, and ZCQ significantly different between the 2 groups. The majority of patients in the 2 groups had Grade 1 spondylolisthesis (82.1\% vs $88.9 \%)$ occurring at the L4-5 level $(89.7 \%$ vs $75.6 \%$ for SVA $<50 \mathrm{~mm}$ vs SVA $\geq 50 \mathrm{~mm}$, respectively). However, multiple levels of spondylolisthesis $(20.0 \%$ vs $5.1 \%, \mathrm{p}=0.044)$ and spondylolisthesis at the L3-4 level ( $31.1 \%$ vs $12.8 \%, p=0.046)$ were more common among patients in the SVA $\geq 50 \mathrm{~mm}$ group. There was no significant difference in preoperative LL between the groups $\left(51.2^{\circ}\right.$, range $24^{\circ}-72^{\circ}$ for $\mathrm{SVA}<50 \mathrm{~mm}$ vs $47.7^{\circ}$, range $22^{\circ}-71^{\circ}$ for $\mathrm{SVA} \geq 50 \mathrm{~mm}$; $\mathrm{p}=0.228$ ).

In the overall cohort, $65.5 \%$ of patients had a posterior interbody fusion, and $29.8 \%$ had an instrumented (pedicles screw rod construct) posterolateral intertransverse process fusion (Table 2). The rates of posterior interbody fusion and instrumented posterolateral fusion were similar among participants in both groups $(p=0.732)$. Multiple levels of fusion occurred more frequently among patients in the SVA $\geq 50 \mathrm{~mm}$ group (33.3\% vs $12.8 \%, \mathrm{p}=0.028$ ).

\section{Patient-Rated Outcome Measures}

The overall results of the various outcome measures adjusted for multiple levels of spondylolisthesis and multiple levels of fusion (baseline parameters that were significantly different in the univariate analysis) can be seen in Table 3. Patients with an SVA $\geq 50 \mathrm{~mm}$ scored 5.9 points lower on the SF-36 PCS scale (95\% CI 1.0-10.8, $\mathrm{p}=0.018), 8.4$ points higher on the ODI scale $(95 \% \mathrm{CI}-0.3$ to $16.4, \mathrm{p}=$ 0.043 ), and 1.3 points higher on the NRS for back pain 
TABLE 3. Comparison of postoperative outcome measures

\begin{tabular}{lccc}
\hline \multicolumn{1}{c}{ Outcome } & SVA $<50 \mathrm{~mm}$ & SVA $\geq 50 \mathrm{~mm}$ & p Value \\
\hline No. of patients & 39 & 45 & \\
\hline SF-36 PCS & $39.4 \pm 2.4$ & $33.5 \pm 2.1$ & $0.018^{*}$ \\
\hline SF-36 MCS & $54.2 \pm 2.2$ & $53.6 \pm 1.9$ & 0.789 \\
\hline ODI & $21.9 \pm 4.1$ & $30.3 \pm 3.5$ & $0.043^{*}$ \\
\hline NRS & $2.2 \pm 0.6$ & $3.5 \pm 0.5$ & $0.039^{*}$ \\
\hline ZCQ & $2.1 \pm 0.2$ & $2.4 \pm 0.2$ & 0.068 \\
\hline
\end{tabular}

Values adjusted for multiple levels of spondylolisthesis and multiple levels of fusion and expressed as the mean \pm standard error.

* $p<0.05$, SVA $<50 \mathrm{~mm}$ compared with SVA $\geq 50 \mathrm{~mm}$.

(95\% CI $0.07-2.6, \mathrm{p}=0.039)$ and tended to be 0.3 points higher on the ZCQ scale (95\% CI 0.01-0.7, $\mathrm{p}=0.068)$ than those with an SVA $<50 \mathrm{~mm}$, indicating a poorer postoperative outcome. The SF-36 MCS score was not different between groups $(\mathrm{p}=0.789)$.

\section{Postoperative Radiographic Measures}

The ICC scores for assessing the radiographic parameters demonstrated excellent interrater reliability for the 2 radiograph interpreters (Table 4). After controlling for type of surgical procedure, there was no difference between the SVA groups $(<50 \mathrm{vs} \geq 50 \mathrm{~mm})$ in postoperative pelvic incidence (PI), sacral slope (SS), pelvic tilt (PT), or thoracic kyphosis (TK; Table 5). However, postoperative LL and PI-LL were statistically significantly different between the 2 cohorts. In keeping with the above result, $51 \%$ of patients in the cohort with an SVA $\geq 50 \mathrm{~mm}$ had a $\mathrm{LL}<\mathrm{PI}-9^{\circ}$ as compared with $23.1 \%$ in the cohort with an SVA $<50 \mathrm{~mm}(\mathrm{p}=0.013)$. In the post hoc analysis, patients with multiple levels of spondylolisthesis had a significantly greater SVA $(p=0.004)$ and tended to have a smaller postoperative LL $(p=0.091)$, greater instrumentation angle $(\mathrm{p}=0.054)$, and inadequate PI to LL relationship (LL < PI - 9, $\mathrm{p}=0.061$; Table 6).

\section{Correlation of Radiographic Parameters With Outcomes}

The SVA negatively correlated with SF-36 PCS ( $\mathrm{r}=$ $-0.263, \mathrm{p}=0.017)$ and positively correlated with ODI $(\mathrm{r}=$ $0.217, p=0.049$ ), suggesting that, as SVA becomes more positive, physical function declines and spine-specific disability worsens. Thoracic kyphosis and the NRS for intensity of back pain were negatively correlated such that the higher the TK, the more pain the patient experienced $(\mathrm{r}=-0.238, \mathrm{p}=0.031)$. A higher postoperative PI and LL correlated with a higher SF-36 MCS score $(\mathrm{r}=0.252, \mathrm{p}=$ 0.022 and $\mathrm{r}=0.282, \mathrm{p}=0.010$, respectively).

\section{Discussion}

It is well accepted that spinopelvic alignment is important to postoperative outcome for adult spinal deformity and isthmic spondylolisthesis surgery., $1,5,7,11,15,20,21$ To the best of our knowledge, however, this has not been well studied in a surgical cohort with degenerative spondylolisthesis; the literature has included review articles, ${ }^{12,13,16}$ a retrospective review comprising a heterogeneous cohort
TABLE 4. Interrater variability of postoperative radiographic parameters

\begin{tabular}{lc}
\hline \multicolumn{1}{c}{ Parameter } & ICC \\
\hline PI & 0.995 \\
\hline PT & 0.993 \\
\hline SS & 0.993 \\
\hline Sagittal balance & 0.997 \\
\hline TK & 0.994 \\
\hline LL & 0.999 \\
\hline Instrumentation angle & 0.912 \\
\hline
\end{tabular}

with lumbar fusions,,$^{14,23}$ and a pilot study.$^{10}$ This is especially pertinent because surgery for degenerative spondylolisthesis with spinal stenosis is a common and successful procedure. ${ }^{24}$ In accordance with previous deformity studies, our study has shown that patient-rated outcome is influenced by overall postoperative sagittal balance as defined by the SVA. ${ }^{16,20,23}$ Achieving an SVA $<50 \mathrm{~mm}$ in the adult scoliosis population has been recommended for optimal postoperative HRQOL.,16,20 Although degenerative spondylolisthesis is a much smaller deformity (than is recognized for the adult deformity populations), our cohort with an SVA $<50 \mathrm{~mm}$ had a significantly improved HRQOL (SF-36 PCS) compared with that in patients with an SVA $\geq 50 \mathrm{~mm}$, as well as a significantly improved ODI, NRS, and ZCQ. This is in contrast to patients who have spinal stenosis without instability, who have been found to derive similar improvements following decompression regardless of their preoperative sagittal balance. ${ }^{3}$ Interestingly, sagittal balance has been found to improve postlumbar decompression in patients with isolated spinal stenosis., ${ }^{4,9}$

The postoperative spinopelvic parameters differing between the SVA cohorts included LL, PI-LL, and LL = PI $\pm 9^{\circ}$, but did not include PI, TK, PT, or instrumentation angle. Therefore, the important relationship between PI and LL as it pertains to achieving an SVA $<50 \mathrm{~mm}$ (previously defined for the spinal deformity population) is valid for the degenerative spondylolisthesis group. ${ }^{20}$ However, in our study population the postoperative mismatch between the PI and LL more common to the SVA $\geq 50 \mathrm{~mm}$ cohort is not the result of an increased PI but rather of a relative insufficient postoperative LL. Therefore, patients with a high PI require more LL postoperatively to maintain sagittal balance and may be under-corrected, as it is more technically challenging to restore a high LL. ${ }^{13}$ Interestingly, the instrumentation angle was not different between the study groups, suggesting that the instrumented fusion itself was not a cause of the deficient LL. Therefore, it stands to reason that these patients were more likely to have a relatively smaller LL preoperatively. Preoperative lordosis was found to differ clinically by approximately $5^{\circ}$ between groups but not statistically so. Unfortunately, because of the retrospective nature of the study, preoperative sagittal balance and PI are not available for review.

The SVA $\geq 50 \mathrm{~mm}$ cohort was more likely to include patients with multiple levels of spondylolisthesis and multiple levels requiring fusion, suggesting that these variables 
TABLE 5. Comparison of postoperative radiographic parameters

\begin{tabular}{lrcl}
\hline \multicolumn{1}{c}{ Parameter } & $<50 \mathrm{~mm}$ & $\geq 50 \mathrm{~mm}$ & p Value \\
\hline No. of patients & 39 & 45 & \\
\hline $\mathrm{PI}\left({ }^{\circ}\right)$ & $56.4 \pm 4.5$ & $57.9 \pm 4.2$ & 0.629 \\
\hline $\mathrm{PT}\left({ }^{\circ}\right)$ & $21.8 \pm 3.2$ & $23.3 \pm 3.0$ & 0.480 \\
\hline $\mathrm{SS}\left(^{\circ}\right)$ & $37.5 \pm 2.8$ & $36.8 \pm 2.6$ & 0.726 \\
\hline $\mathrm{TK}\left({ }^{\circ}\right)$ & $50.1 \pm 4.2$ & $47.1 \pm 3.8$ & 0.283 \\
\hline $\mathrm{LL}\left({ }^{\circ}\right)$ & $56.4 \pm 4.7$ & $49.8 \pm 4.3$ & $0.040^{*}$ \\
\hline $\mathrm{PI}+\mathrm{TK}-\mathrm{LL}\left({ }^{\circ}\right)$ & $50.2 \pm 4.8$ & $55.0 \pm 4.4$ & 0.144 \\
\hline $\mathrm{PI}-\mathrm{LL}\left(^{\circ}\right)$ & $0.2 \pm 4.6$ & $7.9 \pm 4.5$ & $0.022^{*}$ \\
\hline $\mathrm{Instrumentation}$ angle† $\left(^{\circ}\right)$ & $20.5 \pm 1.5$ & $18.5 \pm 1.4$ & 0.315 \\
\hline $\mathrm{LL}<\mathrm{PI}-9^{\circ}$ & $9(23.1)$ & $23(51.1)$ & $0.013^{*}$ \\
\hline $\mathrm{LL} \geq \mathrm{PI} \pm 9^{\circ}$ & $30(76.9)$ & $22(48.9)$ & \\
\hline
\end{tabular}

Values are adjusted for type of surgical procedure and expressed as the mean \pm standard error or as number (\%).

${ }^{*} p<0.05$, SVA $<50 \mathrm{~mm}$ compared with SVA $\geq 50 \mathrm{~mm}$

† Instrumentation angle is provided for 79 patients: 38 in the SVA $<50 \mathrm{~mm}$ group and 41 in the SVA $\geq 50 \mathrm{~mm}$ group.

may be risk factors for insufficient postoperative LL and a resulting positive sagittal imbalance. A further post hoc analysis supported this assertion as patients with multiple levels of spondylolisthesis had a significantly higher SVA and tended to have a smaller postoperative LL, instrumentation level, and inadequate PI to LL relationship (LL < PI $\left.-9^{\circ}\right)$. The indication for and goal of surgery in this patient cohort was treatment of the symptomatic spinal stenosis and associated degenerative spondylolisthesis, and no attempt was made to address a "degenerative flat back." Unfortunately, this study found that the overall LL but not the instrumentation angle was significantly different between cohorts, suggesting that a much more extensive surgery may be necessary to account for the sagittal decompensation than would otherwise be required to treat the neurogenic claudication and radiculopathy. A recent study has confirmed that fusion for lumbar degenerative disease is much more likely to improve spinopelvic parameters and balance if it involves a long fusion compared with a short fusion. ${ }^{14}$ Certainly, further multicenter prospective studies should be performed before such a large change in surgical practice could be justified for the treatment of lumbar degenerative spondylolisthesis.

Previous authors have discussed the importance of obtaining a PT $<20^{\circ} .1,16,20$ A PT $>20^{\circ}$ with a positive SVA is thought to reflect a retroverted pelvis and sagittal imbalance. Kim et al. noted in their study of degenerative spondylolisthesis patients that those whose PT improved after surgery had greater improvements in their NRS and ODI scores..$^{10}$ In our study we found no difference in PT between the SVA $<50 \mathrm{~mm}$ group and $\mathrm{SVA} \geq 50 \mathrm{~mm}$ group, nor a correlation between PT and patient-rated outcomes. However, both of our study cohorts had a mean PT $>20^{\circ}$ and a positive SVA, which likely explains the lack of difference between our study groups.

To our knowledge, this is one of the first studies to evaluate the potential importance of postoperative sagittal balance and spinopelvic parameters in a cohort of patients with degenerative spondylolisthesis treated surgically.
TABLE 6. Comparison of radiographic parameters in patients with single-level versus multiple-level spondylolisthesis

\begin{tabular}{|c|c|c|c|}
\hline Parameter & $\begin{array}{c}\text { Single-Level } \\
\text { Spondylolisthesis }\end{array}$ & $\begin{array}{c}\text { Multiple-Level } \\
\text { Spondylolisthesis }\end{array}$ & $p$ Value \\
\hline No. of patients & 73 & 11 & \\
\hline $\operatorname{LL}\left({ }^{\circ}\right)$ & $50.4 \pm 14.3$ & $42.5 \pm 13.4$ & 0.091 \\
\hline SVA (mm) & $55.3 \pm 38.5$ & $93.1 \pm 42.5$ & $0.004^{*}$ \\
\hline $\begin{array}{l}\text { Instrumentation } \\
\text { angle }\left(^{\circ}\right)\end{array}$ & $19.2 \pm 8.5$ & $24.7 \pm 9.5$ & 0.054 \\
\hline $\mathrm{LL}<\mathrm{PI}-9^{\circ}$ & $25(34.2)$ & $7(63.6)$ & 0.061 \\
\hline $\mathrm{LL} \geq \mathrm{PI} \pm 9^{\circ}$ & $48(65.8)$ & $4(36.4)$ & \\
\hline
\end{tabular}

Values expressed as mean \pm standard error or as number (\%).

${ }^{*} p<0.05$, single compared with multiple levels of spondylolisthesis.

$\dagger$ Instrumentation angle is provided for 79 patients: 38 with SVA $<50 \mathrm{~mm}$ and

41 with SVA $\geq 50 \mathrm{~mm}$.

However, it was a retrospective review of prospectively collected data, which has the inherent flaws of any such clinical study design including loss to follow-up, incomplete radiographic follow-up without preoperative 36-inch films, and nonrandomized treatment allocation. Despite the retrospective nature of this study, the demographics were similar between groups apart from the multiple-level spondylolisthesis and fusions, the data collection was standardized, and the radiographic analysis was valid and reproducible as indicated by the high interobserver reliability measures. The majority of the study population had single-level spondylolisthesis and fusion at the L4-5 level, which may impact the generalizability of the study. As patients with multiple-level spondylolisthesis and fusions were more common to the SVA $\geq 50 \mathrm{~mm}$ cohort, these potential risk factors should be further investigated with a larger powered prospective study. Another limitation is that the indications for surgery and the surgical technique were not standardized a priori. Based on the recognized practice standards of the time, almost all patients in this cohort were treated with fusion and decompression. ${ }^{17} \mathrm{Al}-$ though no specific algorithm was used, the general approach was to perform an interbody fusion if indirect foraminal decompression or local kyphosis correction was required or if a posterolateral fusion was deemed less likely to occur (that is, inadequate fusion bed). Finally, preoperative 36-inch imaging was not routinely performed for this cohort; therefore, whether the sagittal imbalance was preexisting or developed postoperatively is unknown. However, we now recommend 36-inch imaging studies preoperatively at least to inform the decision-making process and expectations.

\section{Conclusions}

Our study has found that patient-rated outcome is influenced by overall postoperative sagittal balance as defined by the SVA. This suggests that for patients with degenerative lumbar spondylolisthesis, overall sagittal balance and spinopelvic parameters should be considered during operative planning and counseling to patient expectations with respect to expected improvements in pain, function, and HRQOL. 


\section{References}

1. Ames CP, Smith JS, Scheer JK, Bess S, Bederman SS, Deviren $\mathrm{V}$, et al: Impact of spinopelvic alignment on decision making in deformity surgery in adults: a review. J Neurosurg Spine 16:547-564, 2012

2. Barrey C, Jund J, Perrin G, Roussouly P: Spinopelvic alignment of patients with degenerative spondylolisthesis. Neurosurgery 61:981-986, 2007

3. Bayerl SH, Pöhlmann F, Finger T, Onken J, Franke J, Czabanka M, et al: The sagittal balance does not influence the 1 year clinical outcome of patients with lumbar spinal stenosis without obvious instability after microsurgical decompression. Spine (Phila Pa 1976) 40:1014-1021, 2015

4. Fujii K, Kawamura N, Ikegami M, Niitsuma G, Kunogi J: Radiological improvements in global sagittal alignment after lumbar decompression without fusion. Spine (Phila Pa 1976) 40:703-709, 2015

5. Glassman SD, Berven S, Bridwell K, Horton W, Dimar JR: Correlation of radiographic parameters and clinical symptoms in adult scoliosis. Spine (Phila Pa 1976) 30:682-688, 2005

6. Grevitt M, Khazim R, Webb J, Mulholland R, Shepperd J: The Short Form-36 Health Survey Questionnaire in spine surgery. J Bone Joint Surg Br 79:48-52, 1997

7. Hresko MT, Labelle H, Roussouly P, Berthonnaud E: Classification of high-grade spondylolistheses based on pelvic version and spine balance: possible rationale for reduction. Spine (Phila Pa 1976) 32:2208-2213, 2007

8. Hudak PL, Wright JG: The characteristics of patient satisfaction measures. Spine (Phila Pa 1976) 25:3167-3177, 2000

9. Jeon CH, Lee HD, Lee YS, Seo HS, Chung NS: Change in sagittal profiles after decompressive laminectomy in patients with lumbar spinal canal stenosis: a 2-year preliminary report. Spine (Phila Pa 1976) 40:E279-E285, 2015

10. Kim MK, Lee SH, Kim ES, Eoh W, Chung SS, Lee CS: The impact of sagittal balance on clinical results after posterior interbody fusion for patients with degenerative spondylolisthesis: a pilot study. BMC Musculoskelet Disord 12:69, 2011

11. Lafage V, Schwab F, Patel A, Hawkinson N, Farcy JP: Pelvic tilt and truncal inclination: two key radiographic parameters in the setting of adults with spinal deformity. Spine (Phila Pa 1976) 34:E599-E606, 2009

12. Lamartina C, Berjano P, Petruzzi M, Sinigaglia A, Casero G, Cecchinato R, et al: Criteria to restore the sagittal balance in deformity and degenerative spondylolisthesis. Eur Spine J 21 (Suppl 1):S27-S31, 2012

13. Le Huec JC, Faundez A, Dominguez D, Hoffmeyer P, Aunoble S: Evidence showing the relationship between sagittal balance and clinical outcomes in surgical treatment of degenerative spinal diseases: a literature review. Int Orthop 39:87-95, 2015 (SICOT)

14. Liu H, Li S, Wang J, Wang T, Yang H, Li Z, et al: An analysis of spinopelvic sagittal alignment after lumbar lordosis reconstruction for degenerative spinal diseases: how much balance can be obtained? Spine (Phila Pa 1976) 39:B52-B59, 2014

15. Mac-Thiong JM, Transfeldt EE, Mehbod AA, Perra JH, Denis F, Garvey TA, et al: Can C7 plumbline and gravity line predict health related quality of life in adult scoliosis? Spine (Phila Pa 1976) 34:E519-E527, 2009

16. Mehta VA, Amin A, Omeis I, Gokaslan ZL, Gottfried ON:
Implications of spinopelvic alignment for the spine surgeon. Neurosurgery 70:707-721, 2012

17. North American Spine Society: Evidence-Based Clinical Guidelines for Multidisciplinary Spine Care: Diagnosis and Treatment of Degenerative Lumbar Spondylolisthesis, ed 2. Burr Ridge, IL: North American Spine Society, 2014 (https://www.spine.org/researchclinicalcare/quality improvement/clinicalguidelines.aspx) [Accessed November 3, 2016]

18. Roland M, Fairbank J: The Roland-Morris Disability Questionnaire and the Oswestry Disability Questionnaire. Spine (Phila Pa 1976) 25:3115-3124, 2000

19. Schuller S, Charles YP, Steib JP: Sagittal spinopelvic alignment and body mass index in patients with degenerative spondylolisthesis. Eur Spine J 20:713-719, 2011

20. Schwab F, Patel A, Ungar B, Farcy JP, Lafage V: Adult spinal deformity-postoperative standing imbalance: how much can you tolerate? An overview of key parameters in assessing alignment and planning corrective surgery. Spine (Phila Pa 1976) 35:2224-2231, 2010

21. Schwab FJ, Blondel B, Bess S, Hostin R, Shaffrey CI, Smith JS, et al: Radiographical spinopelvic parameters and disability in the setting of adult spinal deformity: a prospective multicenter analysis. Spine (Phila Pa 1976) 38:E803-E812, 2013

22. Stucki G, Daltroy L, Liang MH, Lipson SJ, Fossel AH, Katz JN: Measurement properties of a self-administered outcome measure in lumbar spinal stenosis. Spine (Phila Pa 1976) 21:796-803, 1996

23. Videbaek TS, Bünger CE, Henriksen M, Neils E, Christensen FB: Sagittal spinal balance after lumbar spinal fusion: the impact of anterior column support results from a randomized clinical trial with an eight- to thirteen-year radiographic follow-up. Spine (Phila Pa 1976) 36:183-191, 2011

24. Weinstein JN, Lurie JD, Tosteson TD, Zhao W, Blood EA, Tosteson AN, et al: Surgical compared with nonoperative treatment for lumbar degenerative spondylolisthesis. Fouryear results in the Spine Patient Outcomes Research Trial (SPORT) randomized and observational cohorts. J Bone Joint Surg Am 91:1295-1304, 2009

\section{Disclosures}

The authors report no conflict of interest concerning the materials or methods in this study or the findings specified in this paper.

\section{Author Contributions}

Conception and design: CS Bailey, Gurr, SI Bailey. Acquisition of data: CS Bailey, Radovanovic, Ganapathy, Gurr, SI Bailey. Analysis and interpretation of data: CS Bailey, Radovanovic, Urquhart, Ganapathy. Drafting the article: CS Bailey, Radovanovic, Urquhart. Reviewed submitted version of manuscript: all authors. Approved the final version of the manuscript on behalf of all authors: CS Bailey. Statistical analysis: Urquhart. Administrative/technical/material support: Urquhart. Study supervision: CS Bailey, Siddiqi, Gurr, SI Bailey.

\section{Correspondence}

Christopher S. Bailey, E1 317 Victoria Hospital, 800 Commissioners Rd. East, London, ON N6A 5W9, Canada. email: chris. bailey@lhsc.on.ca. 